\title{
Live Fibular Graft for the Treatment of Long Bone Tumors in Children
}

\author{
Seung-Koo Rhee ${ }^{*}$, Mohammed Einayet Abdelhameed ${ }^{2}$, Chi-Hoon Ahn1, Cheol-U Kim¹ \\ ${ }^{1}$ Department of Orthopaedic Surgery, Bone \& Joint Tumor Division, Daejeon Sun Medical Center, Daejeon, Korea \\ ${ }^{2}$ Department of Orthopaedic Surgery, Sharg Alneel Hospital, Khartom, Sudan \\ Email: *skrhee@catholic.ac.kr
}

How to cite this paper: Rhee, S.-K., Abdelhameed, M.E., Ahn, C.-H. and Kim, C.-U. (2017) Live Fibular Graft for the Treatment of Long Bone Tumors in Children. Journal of Cancer Therapy, 8, 225-233.

https://doi.org/10.4236/jct.2017.83019

Received: January 11, 2017

Accepted: March 3, 2017

Published: March 6, 2017

Copyright $\odot 2017$ by authors and Scientific Research Publishing Inc. This work is licensed under the Creative Commons Attribution International License (CC BY 4.0).

http://creativecommons.org/licenses/by/4.0/

\begin{abstract}
Purposes: We would like to inform the characteristics of recurred osteo-fibrous dysplasia (OFD), and also the possible use of vascularized composite autograft and allografts (VCA) combined with live fibular graft (LFG) for the treatment of aggressive benign bone tumor and osteogenic sarcomas in children. Materials and Methods: We reviewed one boy with recurred OFD after LFG, and other four children with osteogenic sarcoma in long bone which was treated with LFG and VCA, and followed them for average 9 years (3 - 14 years). Survival of the LFG and VCA was estimated by the ISOLS Functional Radiologic Scoring System, but not with Kaplans-Meier's scoring system because of a small series of case reports. Results: All succeed after surgeries initially, but the cause of recurrence of OFD was still unclear, and one girl with osteogenic sarcoma on distal femur died with skip and lung metastasis, 4 years after surgeries. Conclusions: The causes of recurred OFD are not found thru pathologic studies of our patient, but we believe the multifocal origin of tumor cells even on the adjacent soft tissues in OFD is one of the causes. The excised long bone tumor is recycled by pasteurization or autoclaving, or allograft, then LFG, and neo-adjuvant chemotherapy would be one of elective surgery for the treatment of malignant long bone tumors in children. The LFG into recycled autograft or allograft bone is difficult to perform simultaneously, but very effective to increase more earlier regenerative vascularities and also the stabilities of the dead bones in children.
\end{abstract}

\section{Keywords}

Live Fibular Graft, Vascularized Composite Allograft or Autograft, Osteofibrous Dysplasia, Osteogenic Sarcoma, Children

\section{Introduction}

The prognosis and treatment of childhood cancers may behave very differently 
from adult cancers, even they start in the same part of body. And the surgical ways should be taken into account seriously because of their growth. Tumor excision with wide surgical margins is the primary essential goals of treatment for some aggressive or recurrent benign or malignant bone tumors. This requires an aggressive surgical resection with potentially large osseous defects. Functional reconstructive options for such large osseous defects include structural recycled autografts or allograft transplantation [1] [2], arthroplasty [3] [4], and composite reconstruction using allografts and metal prosthesis [5] [6] and so on.

As diagnostic and therapeutic techniques improve, patients with musculoskeletal sarcoma should expect increased survival rate, decreased complications and side effects, and an improved quality of life. Functional longevity of reconstruction including their normal growing becomes a major concern, especially in children and physically active patients. The growing disturbance due to bone tumor is another problem in children, as the epiphyseal growth plate should be preserved as possible.

The LFG only, or combined with the vascularized composite autograft or allograft (VCA) could be done for the treatment of malignant bone tumors as combined complex surgical procedures, i.e. wide tumor excision associated with LFG simultaneously into the devitalized tumor bone which was treated with the recycling by pasteurization or autoclaving, or allograft. It must be one of demanding operations, but we can expect it will induce more rapid bony union between host and grafted bones, rapid revascularization and stabilities of dead bone. And then, post-operative immobilization will also be shortened. But the VCA associated LFG is very difficult because of long operation time for more than average 5 hours in our series, and also possible high surgical risks and complications.

We had experienced the one case of aggressive benign bone tumor, OFD, and 4 cases of osteogenic sarcoma, which were treated with LFG only, or VCA with combined LFG after tumor resection, and followed them for average 9 years (3 years to 14 years).

\section{Materials and Methods}

One of osteofibrous dysplasia (OFD), 7 year old boy, and four osteogenic sarcoma, Enneking's type IIB [7], 3 girls and one boy, aged 8 - 13 years old, were treated with LFG and VCA (Table 1). The immediate biopsy, adjuvant 2 or 3 combined chemotherapy for 6 - 8 weeks, wide resection of long bone tumor, reconstructed the bony defect with LFG only (Case 1), allograft combined with LFG in 2 cases (Cases 3 and 4), autoclaved and pasteurized recycled autograft combined with LFG in each 1case (Cases 2 and 5) (Table 1), and the neo-adjuvant chemotherapy for 12 weeks are the main procedure.

After confirm the pathologic tumor necrosis areas for osteogenic sarcoma cases from excised whole tumor mass indicating the effect of preoperative chemotherapy, and re-start with the same agents in 3 children, but Case 2 was changed with new neo-adjuvant agents for at least 12 weeks more. The skip and finally lung metastasis in Case 2 girl was found and died in 4 years after operationtion. The partial 
Table 1. Cases analysis and results.

\begin{tabular}{|c|c|c|c|c|c|c|c|}
\hline No. & Age & Sex & Diagnosis & Treatment & Results & Second Op. & End Results \\
\hline 1 & $\begin{array}{l}7 \text { year old } \\
\text { (Case 1) }\end{array}$ & M & $\begin{array}{l}\text { OFD } \\
\text { (tibia) }\end{array}$ & Excision + LFG & Recur. & $\begin{array}{l}\text { Excision } \\
+ \text { Allograft }\end{array}$ & Good 14 yr F/U \\
\hline 2 & $\begin{array}{l}10 \text { year old } \\
(\text { Case } 2)\end{array}$ & $\mathrm{F}$ & $\begin{array}{l}\text { Osa. } \\
\text { (femur) }\end{array}$ & $\begin{array}{c}\text { Autoclaved } \\
\text { Autograft + LFG }\end{array}$ & Skip Meta. & $\begin{array}{l}\text { Excision } \\
+ \text { Allograft }\end{array}$ & $\begin{array}{l}\text { Limb } \\
\text { Shortening, } \\
\text { Lung Meta. } \\
\text { Death, } 4 \text { yr Later }\end{array}$ \\
\hline 3 & $\begin{array}{c}13 \text { year old } \\
\text { (Case } 3)\end{array}$ & $\mathrm{F}$ & $\begin{array}{c}\text { Osa. } \\
\text { (femur) }\end{array}$ & $\begin{array}{c}\text { Excision + } \\
\text { Allograft + LFG }\end{array}$ & United & - & $\begin{array}{c}\text { Good Well } \\
\text { Maintained } \\
7 \text { yr F/U }\end{array}$ \\
\hline 4 & 10 year old & M & $\begin{array}{c}\text { Osa. } \\
\text { (femur) }\end{array}$ & $\begin{array}{c}\text { Excision + } \\
\text { Allograft + LFG }\end{array}$ & United & - & $\begin{array}{c}\text { Good } \\
\text { Well Maintained } \\
12 \mathrm{yr} \mathrm{F} / \mathrm{U}\end{array}$ \\
\hline 5 & 8 year old & $\mathrm{F}$ & $\begin{array}{c}\text { Osa. } \\
\text { (femur) }\end{array}$ & $\begin{array}{c}\text { Pasteurized } \\
\text { Autograft + LFG }\end{array}$ & United & - & $\begin{array}{c}\text { Good } \\
\text { Well Maintained } \\
3 \mathrm{yr} \mathrm{F} / \mathrm{U}\end{array}$ \\
\hline
\end{tabular}

*OFD: Osteo-fibrous dysplasia, Osa.: Osteogenic sarcoma, LFG: Live fibular graft, Meta.: Metastasis.

weight bearing with crutches was permit on average 3 months after operation. We followed them for average 9 years (3 - 14 years). And their end result was measured by serial radiological ISOLS evaluations [8].

\section{Results}

Their clinical end results could be determined by the patient's joint motion, limb shortening, pain on motions, crutches or cane walks and simply ISOLS radiologic serial changes with MRI or PET-CT.

The Case 1, OFD, showed unusual recurrence even after the complete excision of lesion and LFG, and we did not find any particular histochemical evidences of recurrence (Figure 1 and Table 1).

Three out of four cases of osteogenic sarcoma were analyzed as favorable by ISOLS serial radiologic evaluations at average 9 years follow-up ( 3 - 14 years), but another Case 2 (Figure 2) associated with post-operative $4 \mathrm{~cm}$ limb shortening showed poor results with skip lesion in one year, re-allograft and lung metastasis in four years after surgeries (Figure 2).

\section{Cases Report}

Case 1: (Figure 1(a) and Figure 1(d)) A 7-year-old boy. Osteo-Fibrous Dysplasia (OFD) (A case of tumor excision, LFG, first, and allograft for late recurrence).

This boy slipped down and was broken his right tibia. It was pathologic fracture induced by anterior bowing, shin splint and poly-ostotic cysts on tibia shaft for last 2 years, not treated (Figure 1(a)). The LFG from opposite fibula after wide excision of whole tibia was done (Figure 1(b)). One year after LFG, the grafted fibula was united well and hypertrophied, but seems to recur with similar preoperative cystic changes (Figure 1(c)). Two years later, the recurred OFD was re-established. We don't know yet the exact causes of recurrence in OFD, and all pathologic findings did not give us any evidences of recurrences, but we believe that it's pathologic characteristics of osteoid and fibroblasts of OFD in 


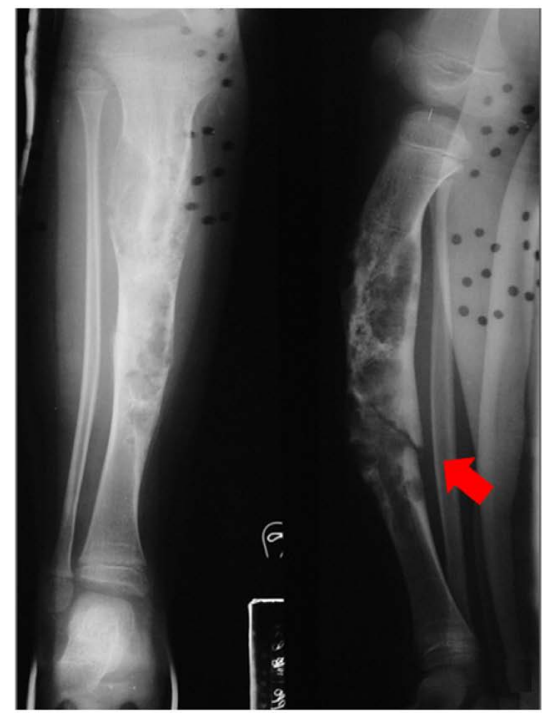

(a)

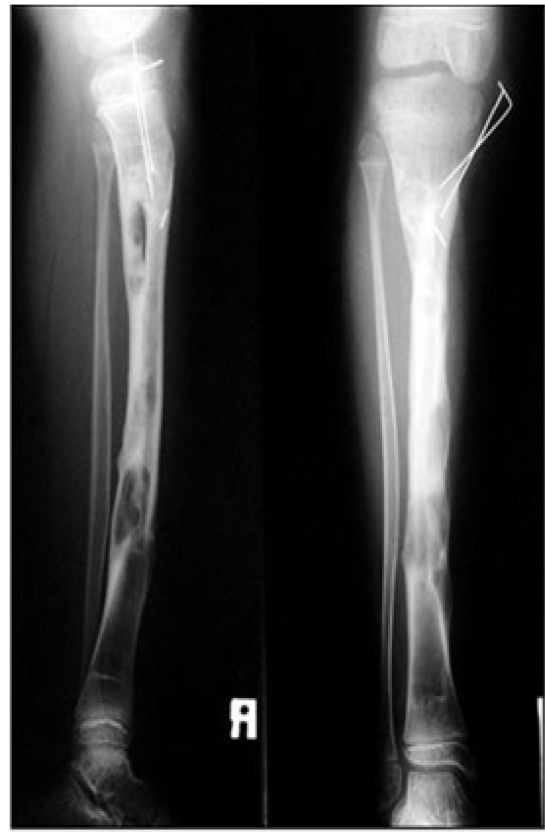

(c)

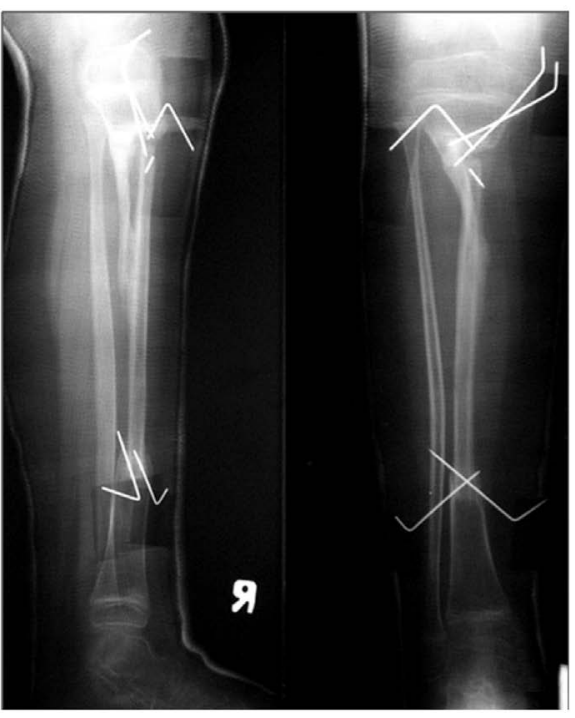

(b)

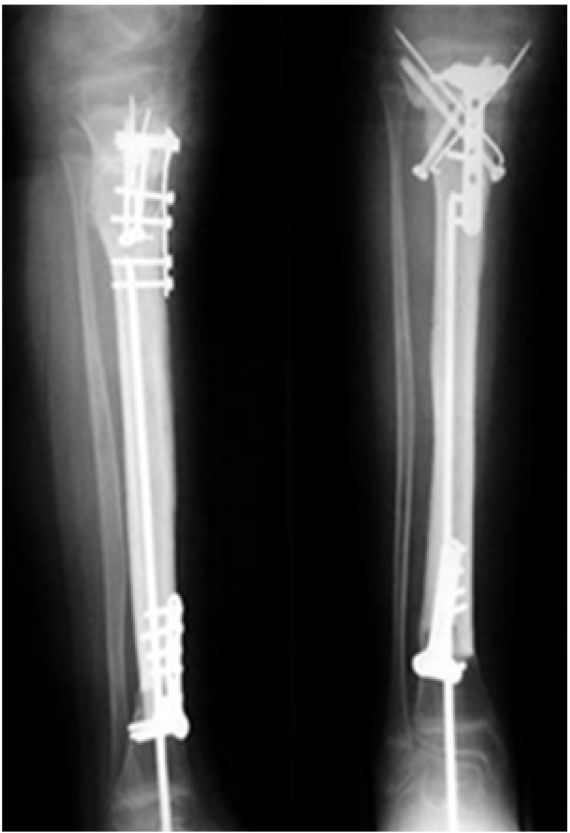

(d)

Figure 1. A 7-year-old boy. Osteo-Fibrous Dysplasia (OFD) (A case of tumor excision, LFG, first, and allograft for late recurrence). (a) Poly-ostotic cysts, shin splint with shaft fracture suggesting OFD; (b) LFG from opposite leg after wide excision of affected tibia; (c) One year after the LFG, solid union and hypertrophied grafted fibula but recurred OFD was recurred; (d) 9 months after the allograft after complete excision of tibia, solid bony union was obtained. The end result in 14 years follow-up was good.

which originated multifocally from periosteum and even adjacent soft tissues too, and so inevitable to incomplete excision at the first operation. Complete re-excision of recurred OFD and allograft was done again (Figure 1(d)), and finally obtain the solid bony union on 9 months after allograft and cancellous chip bone grafts together (Figure 1(d)). The end result was good on 14 years follow-up (Table 1). 


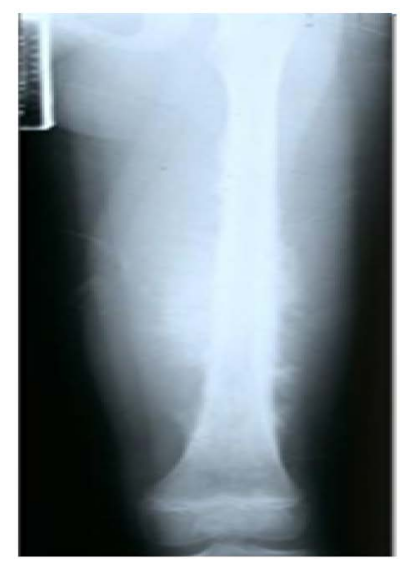

(a)

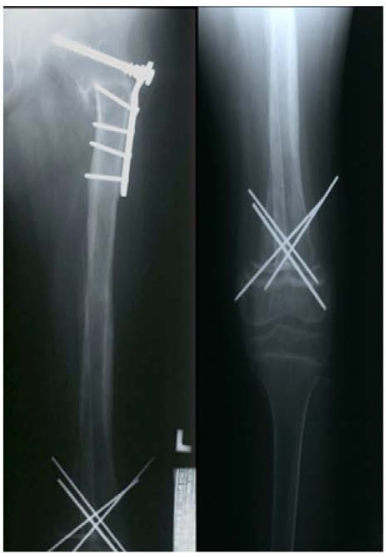

(c)

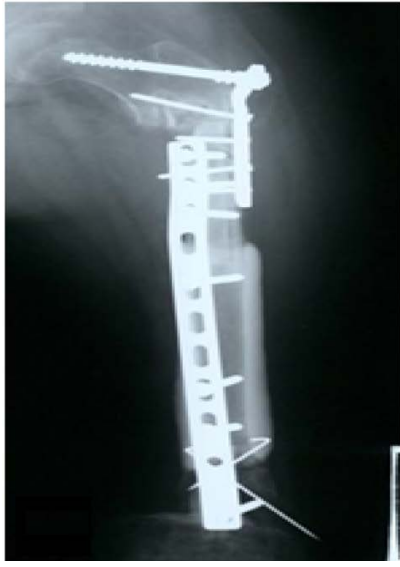

(e)

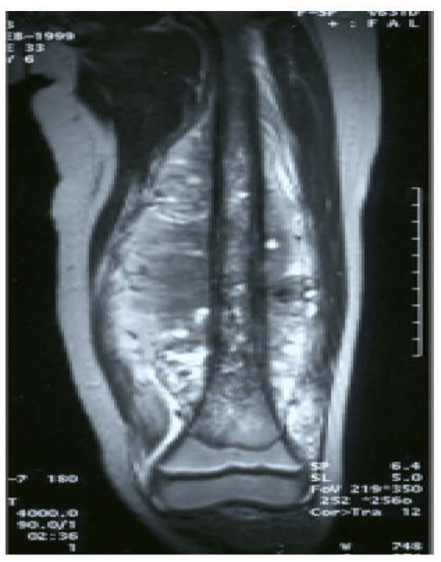

(b)

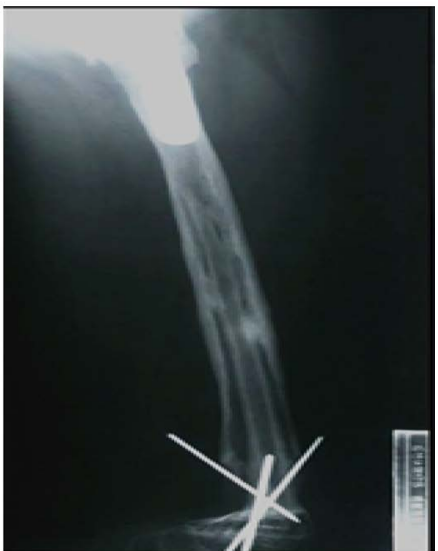

(d)

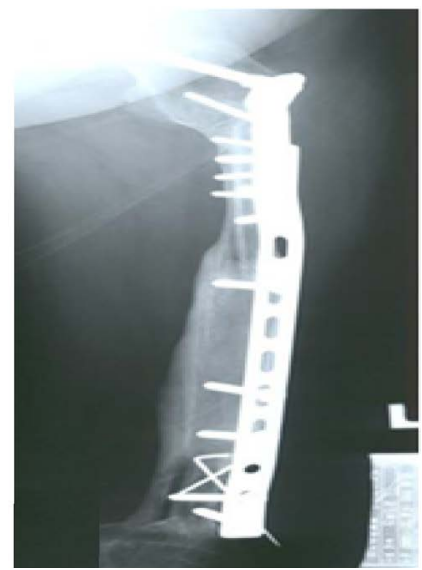

(f)

Figure 2. A 10-year-old girl. Osteogenic sarcoma on left femur (A case of autoclaved autograft and LFG simultaneously, but skip metastasis and allograft later). (a) An osteogenic osteosarcoma involving whole femur; (b) An extensive soft tissue invasion on MRI, but no metastatic lesions; (c) After 10 weeks of combined chemotherapy, the affected femur was excised and recycled by autoclaving, getting back at same place combined with LFG; (d) One year later, an unusual skip metastasis was found on recycled femur, but no lung or other metastatic lesions; (e) Whole femur was excised again, replaced with allograft with shortening, and 6 months later, autogenous iliac chip bone graft was done on proximal femur; (f) One year later, solid bone union with $4 \mathrm{~cm}$ limb shortening was obtained, but 4 years later, the lung metastasis was found. The end result was poor. 
Case 2: (Figures 2(a)-(f)) A 10-year-old girl. Osteogenic sarcoma on left femur (A case of autoclaved autograft and LFG simultaneously, but skip metastasis and allograft later).

Severe painful swelling on whole femur was noted for 6 months. X-ray and MRI show an extensive osteoblastic osteogenic sarcoma (Figure 2(a) and Figure 2(b)).

After confirmed biopsy, combined chemotherapy with high dose of methotrexate and adriamycin for 10 weeks was given. And then, recycled autograft of affected whole femur by autoclaving and LFG into the medullary canal of replaced autoclaved femur was performed simultaneously (Figure 2(c)), and another 12 weeks of hip spicacast immobilization and neo-adjuvant chemotherapy were also given.

The distal epiphysis of affected femur was preserved for her growing. The surgical wound and her general conditions were good.

But one year after, an unusual skip metastasis, may be surgically contaminated, was found on recycled femur by autoclaving (Figure $2(\mathrm{~d})$ ), but no lung or other metastasis. Immediately, whole affected femur was excised and replaced with allograft, fixed it with plates (Figure 2(e)).

Six months later, the delayed union was treated with autogenous cancellous chip bone grafts from ilium. One year after, solid bony union, and $4 \mathrm{~cm} \mathrm{limb}$ shortening was obtained. But four years later, the end result was poor with lung metastasis, and she died (Table 1).

Case 3: (Figure 3(a) and Figure 3(b)) A 13-year-old girl. Osteogenic sarcoma on left femur (A case of allograft and LFG simultaneously).

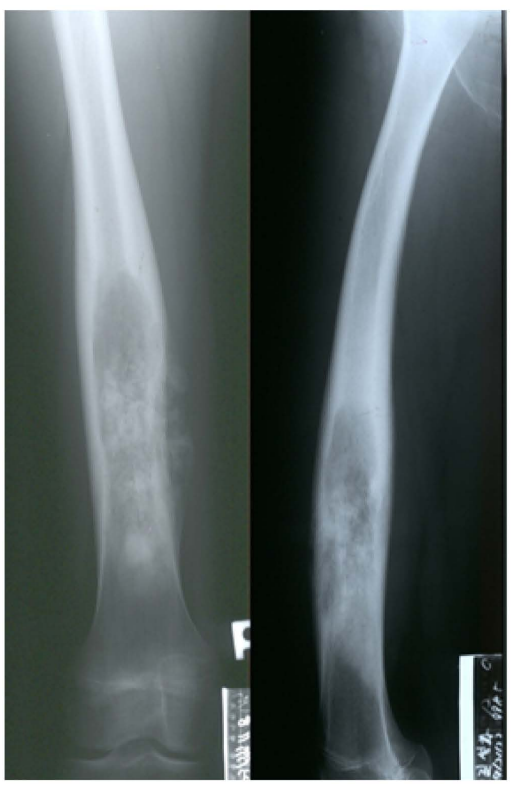

(a)

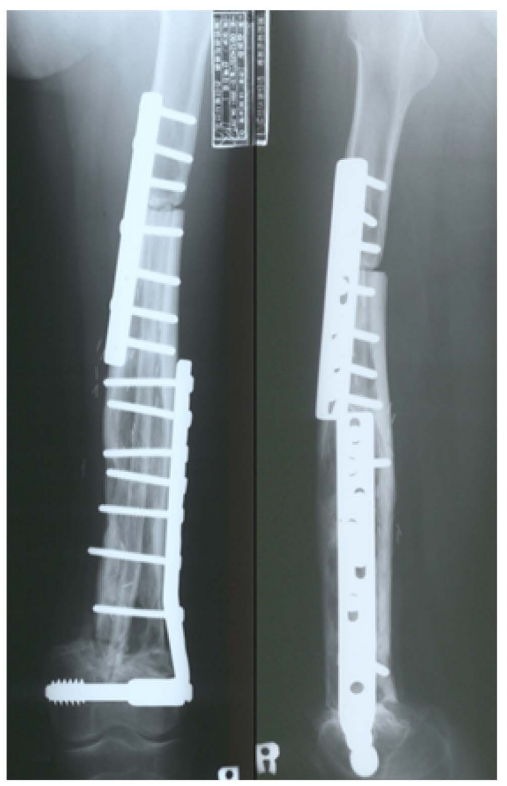

(b)

Figure 3. A 13-year-old girl. Osteogenic sarcoma on left femur (A case of allograft and LFG simultaneously). (a) A typical osteogenic osteosarcoma for 4 months duration on distal femur; (b) After wide excision distal femur but preserved distal epiphyseal plate, an allograft associated with LFG was done simultaneously, eight months after operation, bone was united, and the end result in 7 years follow up is good. 
A typical osteogenic sarcoma on distal femur for 4 months was confirmed by open biopsy, and 7 weeks of neo-adjuvant combined chemotherapy with high dose methotrexate and adriamycin were given (Figure 3(a)).

We had performed the wide excision of affected distal femur; long segment of allograft associated with intramedullary LFG at same time, and preserved the distal femoral epiphyseal plate but worried about too many screws to LFG site for stable fixation, possibly inducible vascular impairment. But eight months after operation, the grafted allograft was united well and partial walking was possible (Figure 3(b)).

The end result by ISOLS radiologic criteria was good in 7 years follow-up.

\section{Discussion}

Limb salvage procedure for long bone tumor, especially in children, is one of the most demanding reconstructions. Our study had certain limitations with only few different tumor cases in children. But we would like to inform the unusual varieties of children's tumors, osteofibrous dysplasia (OFD) which was showed very unusual recurrence by unknown pathologic tumor characteristics, and osteogenic sarcomas which was treated with difficult surgical procedures using the LFG and VCA even in children.

The causes of an unusual recurrence of OFD in this study are not clear, but it may be suggest that the pathologic characteristics of osteoblast and fibroblast in tumor tissues which has multifocal tumor cellorigins on periosteum and the adjacent soft tissue too, and also incomplete tumor excision could be one of the causes of recurrences.

It's important to consider the availability of each surgical procedures (recycled autograft, allograft, prosthesis or their combination), and the level of surgical difficulty, morbidity, incidence of complications, prognosis of the various reconstructions in this anatomic area, tumor characteristics and also patient's growing especially for the treatment of osteogenic sarcoma in children.

In cases of osteogenic sarcoma, the surgical margins of bone tumor should be decided on MRI carefully, i.e. usually 3 - $4 \mathrm{~cm}$ wide margins for malignant tumors with resistant chemotherapy, or $1-3 \mathrm{~cm}$ marginal excision for less malignancies with sensitive chemotherapeutic treatment. Carefully decide the replacing biologic bone for bone defect site, i.e. autograft, allograft or live bone graft, after wide excision. We usually prefer the recycled autograft by pasteurization for at least $65^{\circ} \mathrm{C}, 30$ minutes of boiling, then autoclaving second for malignant bone tumors. We believe the recycled autograft or allograft associated with LFG and strong stabilizing fixation was best in long segment excised cases especially in children (Table 1, Case 2, and Case 3 ). The cryo-surgery with dip into $-22^{\circ} \mathrm{C}$, three times freezing and thawing, shows still alive the malignant cells partly. The autoclaving will induce the tumor cells totally death but also diminish the mineral architecture for bony strength, inducing delayed bony union or easy to fracture [9] [10].

Expandible tumor prosthesis can also be used for limb lengthening in children, 
and hemi-joint or whole joint allograft including meniscus and ligaments in knee are also available, now [3] [11] [12] [13] but not in children.

The LFG was first reported by Dr. Tayler et al. [14] [15]. It will induce the continuous vas cularities into the dead bone after surgery, rapid osteogenic bony union and also hypertrophy of grafted fibula especially in children. Strong internal and external fixations, not to damages the LFG, are essential to prevent the fractures and delayed union after limb salvage operation. The epiphyseal plate of tumor bone in children must be preserved as possible (Table 1, Case 1, Case 2, and Case 3). Aggressive and advanced malignant tumors with metastasis in Enneking's Type III are not indicated with VCA.

The neo-adjuvant chemotherapy in osteogenic sarcoma patients have made the survival rate much longer, from $25 \%$ of Kaplan-Meier's 5 years survival rate in 1989 to $66 \%$ in 1996, even much improving now, at our hospitals [16] [17].

The comparative results for chemotherapeutic treatment combined with surgical excision of osteogenic sarcoma between Korea and China revealed a bit better in Korea, i.e. 5 year survival rate of Stage II (92.7\%; 91.8\%), 3 years survival rates of Stage III (20\%; 7.1\%) [18].

The vascularized composite recycled autograftor allograft (VCA) associated with LFG in aggressive long bonetumors of children is recommended with favorable results, but seriously consider more strict indications and need to collect cases.

\section{Conclusion}

The live fibular graft (LFG) and also vascularities composite recycled autograft and allograft (VCA) are very effective to replace the bone defect after wide excision of malignant bone tumors even in children's malignant long bone tumors, because of the rapid bony union by continuous vascular supply and regeneration into the death bone, and also to keep the post-surgical stabilities induced by intact LFG.

\section{References}

[1] Mankin, H.J., Gebhart, M.C., Jenning, L.C., Springfield, D.S. and Tomford, W.W. (1996) Long-Term Results of Allograft Replacement in the Management of LongBone Tumors. Clinical Orthopaedics and Related Research, 324, 86-97.

[2] Brien, E.W., Terek, R.M., Healy, J.H. and Lane, J.M. (1994) Allograft Reconstruction after Proximal Tibial Resection for Bone Tumors. Cur Orthop Practice, 303, 116-127.

[3] Grimer, R.J., Carter, S.R., Tillman, R.M., Sneath, R.S., Walker, P.S., Unwin, P.S. and Shewell, P.C. (1999) Endoprosthetic Replacement of Theproximal Tibia. The Bone and Joint Journal, 81, 488-494. https://doi.org/10.1302/0301-620X.81B3.9234

[4] Wu, C.C., Henshaw, R.M., Pritsch, T., Squires, M.H. and Malawar, H.M. (2008) Implant Design and Resection Length after Cement Endoprosthesis Survival in Proximal Tibial Reconstruction. The Journal of Arthroplasty, 23, 886-893. https://doi.org/10.1016/j.arth.2007.07.007

[5] Biau, D.J., Dumaine, V., Babinet, A., Tomeno, B. and Anract, P. (2007) Allograft- 
Prosthesis Composite after Bone Tumor Resection at the Proximal Tibia. Clin Orthop Relat Res., 456, 211-217.

[6] Donati, D., Colangeli, M., Colangeli, S., Di Bella, C. and Merculi, M. (2008) Allograft-Prosthetic Composite in the Proximal Tibia after Bone Tumor Resection. Clinical Orthopaedics and Related Research, 466, 459-465.

https://doi.org/10.1007/s11999-007-0055-9

[7] Enneking, W.F. (1986) A System of Staging Musculoskeletal Neoplasms. Clinical Orthopaedics and Related Research, 204, 9-24.

[8] Glasser, D. and Langlais, F. (1991) The ISOLS Radiological Implant Evaluation System. In: Salvage, L., Ed., Major Reconstructions in Oncologic and Nontumoral Conditions, Springer-Verlag, Heidelberg.

[9] Chang, H., Kim, Y.S., Lee, N.K., Kim, S.K., Lee, K.H., Ko, H.S., Cho, H.R. and Rhee, S.K. (1966) Comparison of Osteogenic Potentials of Deep Freezed, Boiled and Autoclaved Autogenous Long Bone Graftsin Rabbits. J Kor Bone Joint Tumor Soc., 2, 4349.

[10] Kang, Y.K., Kim, J.M., Woo, Y.K., Kwon, S.Y., Kim, S.J. and Rhee, S.K. (1966) Results of Autoclaved Autogenous Segmental Bone Graft for Malignant Bone and Joint Tumor. J Kor Bone Joint Tumor Soc., 2, 58-62.

[11] Muscolo, D.L., Ayerza, M.A., Aponte Tinao, L.A. and Ranalierta, M. (2005) Use of Distal Femoral Osteoarticular Allografts in Limb Salvage Surgery. Journal of Bone \& Joint Surgery, 87, 2449-2455. https://doi.org/10.2106/00004623-200511000-00011

[12] Muscolo, D.L., Ayerza, M.A., Farfalli, G. and Aponte-Tiano, L.A. (2010) Proximal Tibia Osteoarticular Allograft in Tumor Limb Surgery. Clinical Orthopaedics and Related Research, 468, 1396-1404. https://doi.org/10.1007/s11999-009-1186-y

[13] Kang, H.G., Kim, J.H. and Kim, K.G. (2014) Limb Salvage Surgery Using Whole Knee Joint Allograft Reconstruction in Osteosarcoma. Journal of the Korean Orthopaedic Association, 49, 244-249. https://doi.org/10.4055/jkoa.2014.49.3.244

[14] Tayler, G.I., Miler, G.D.H. and Ham, E.J. (1975) Vasularized Fibular Graft. Plastic and Reconstructive Surgery, 55, 45-50.

[15] Tayler, G.I. (1977) A Clinical Technique of Vascularized Fibular Graft. Clin North Am, 8, 87-93.

[16] Kim, J.M., Woo, Y.K., Rhee, S.K., Kim, H.M., Kang, Y.K., Song, S.W., Park, W.J. and Kang, J.W. (1992) Survival Study of Conventional Treatment of Osteogenic Sarcoma. Central Venous Catheters, 1, 232-237.

[17] Kang, Y.K., Kim, H.M., Rhee, S.K., Woo, Y.K., Kim, J.M. and Kim, H.K. (1996) Clinical Results of Neo-Adjuvant Chemotherapy and Surgery on Stage III Bosteogenic Sarcoma. Journal of the Korean Bone and Joint Tumor Society, 2, 111-116.

[18] Chen, W., Wang, W., Zhu, H., Li, K., Piao, X.H., Su, H., Jin, J., Wu, F., Mai, J., Rhee, S.K., Kang, Y.K., Park, W.J., Jung, Y.K., Hur, S.W. and Lee, Y.S. (2006) Long Term Follow up of Advanced Osteogenic Sarcoma in Long Bone Which Treated with Chemotherapy and Surgical Excision. Multicenter Comparative Studies between China and Korea. J Kor Bone Joint Tumor Surg, 12, 48-54. 
Submit or recommend next manuscript to SCIRP and we will provide best service for you:

Accepting pre-submission inquiries through Email, Facebook, LinkedIn, Twitter, etc. A wide selection of journals (inclusive of 9 subjects, more than 200 journals)

Providing 24-hour high-quality service

User-friendly online submission system

Fair and swift peer-review system

Efficient typesetting and proofreading procedure

Display of the result of downloads and visits, as well as the number of cited articles Maximum dissemination of your research work

Submit your manuscript at: http://papersubmission.scirp.org/

Or contact jet@scirp.org 